\title{
Research on Universities Bilingual Teaching Quality Evaluation System Based on CBI
}

\author{
HuiYan Li \\ Management Department, Sanya University, Hainan, P.R.China, 572000
}

HaoWang

Sanya Aviation \& Tourism College, School of Tourism \& Hotel Management, Hainan, P.R.China, 572000

\begin{abstract}
CBI (content-based language instruction) is an instructional theory that entails a combination of course content and language teaching as well as that of academic skill learning and L2 acquisition. Bilingual teaching is the most challenging teaching practice in the field of higher education, the rapid development in recent years spurred particularly concerned about the quality of their teaching, it is an important measure of quality assurance to establish university bilingual education teaching quality evaluation system based on the concept of CBI from teaching resources, teaching process and teaching effectiveness.
\end{abstract}

KEYWORD: CBI; Bilingual teaching; Evaluation system

\section{INTRODUCTION}

Bilingual teaching is one of exploratory, experimental, forward-looking and innovative teaching reform implemented by our colleges and universities. The Ministry of Education develop

《Several Opinions on Strengthening Undergraduate Education to improve the quality of teaching $》$ in 2001, it clearly states that "undergraduate education should create conditions for teaching public and professional courses using English or other foreign languages. The high-tech areas like biotechnology, information technology and financial, legal and other professional which needed by our country to adapt to join WTO must go ahead and strive to within three years, the foreign language courses reach $5 \%$ to $10 \%$ of the open curriculum. The university and professional that temporarily unable directly teach in foreign language can use foreign language textbooks and teach in Chinese in some curriculum, step in place." Chinese universities have responded to the spirit of the Ministry of Education policy and actively promote the development of bilingual teaching, many colleges and universities have formulated relevant bilingual internal policies and incentives measures, aims to promote bilingual teaching practice and improve bilingual education system. Department of Higher Education also organized several nationwide seminars on bilingual education, played an important role to promote bilingual teaching in colleges and universities develop further in the country. Currently, our bilingual teaching has formed a considerable scale and become one of the hotspots of teaching reform in colleges and universities.

However, the rapid development of bilingual teaching in our country will inevitably draw attention to its teaching quality, it is an important measure to establish and improve bilingual teaching bilingual teaching quality evaluation system for protecting the bilingual education teaching quality of universities. Generally speaking, bilingual teaching quality evaluation should reflect the requirements of bilingual teaching curriculum to guide teachers to focus on improving foreign language proficiency, correctly handle the relationship between the two teaching objectives_- subject knowledge and the second language, orchestrate teaching content, flexible use various teaching methods, fully mobilize the enthusiasm of students to learn and continuously improve effectiveness of bilingual teaching. So the article will evaluate the bilingual education teaching quality from three aspects: teaching resources, teaching process and teaching effect.

\section{THE CURRENT CHALLENGES BILINGUAL EDUCATION FACED}

\subsection{It is difficult to grasp course difficulty in teaching process}

In the classroom teaching, how to organically combine Chinese and foreign language is a major challenge the current bilingual teaching faced. Many teachers in the classroom can not grasp the ratio of using the foreign language and often resulting in the 
embarrassing situation that teaching requirements reduce in accordance with the requirements of mother-tongue teaching. In bilingual teaching, how to handle relations with the media language and professional courses teaching is the key to a good quality of teaching.

\subsection{Teachers and the lack of interaction in training process}

Another bottleneck problems encountered in bilingual education is the lack of teacher-student interaction, and some non-language professional teachers dared free to play in class, but according to the pre-designed routines for teaching, the students are passive lectures, and between teachers and students can not freely for communication. Even worse, some teachers have forgotten foreign language just a communication tool, changing the non-language subjects into a foreign language teaching in secondary classes. The bilingual education emphasizes teacher-student interaction and professional knowledge teaching, rather than just listening to a teacher teaching only in the foreign language from start to finish in the class.

\subsection{The different standards and unfair in evaluation process}

At present, "manager" for the evaluation is subject and "to be manager" for the evaluation is object in some existing teaching evaluation system, this not only form a passive view of teaching under the strong management mode, but also unfair. The bilingual education is unlike common teaching and can not be measure with the general teaching evaluation mechanisms. For example, from the evaluation subject, if only evaluated by the professional teacher, it is impossible to make the right bilingual teaching evaluation due to the language barrier. On the other hand, due to the foreign language teachers do not understand the disciplinary standards of a specific branch, it is difficult to make just the right evaluation. In addition, the existing evaluation subjectivity and the weight value under the same index is inconsistencies. Evaluation system will mean the loss of its essential function as a "diagnostic and incentives" if it lacks of impartiality. Thus, how to build fair and rational evaluation mechanisms of bilingual teaching has become a challenge faced by bilingual education.

\section{THE TEACHING RESOURCE EVALUATION}

Teaching resource evaluation is to assess the condition which colleges and universities should have in success implementation of bilingual teaching, the index usually include teachers, textbooks and other teaching resources for evaluation.

\subsection{Teaching staff}

Teachers quality and their ability to use bilingual is a key factor in determining the quality and effectiveness of bilingual education. In large part, successful implementation of bilingual education, the key lies in the quality of teaching staff. Bilingual teachers not only have excellent professional knowledge, but also proficient in using foreign language. Therefore, the choice of bilingual teachers should normally dominated by professional teachers who can be more skilled use of modern educational theory and integrate foreign languages into professional teaching. To evaluate the ability of bilingual teachers should include the index such as teacher education, job title, foreign language usage ability, mastery degree of professional knowledge and the theory, and advanced studies in recent years and other comprehensive consideration.

\subsection{Textbook}

Textbook is the carrier of teaching content and directly affect the effectiveness of bilingual education. If there are no textbooks, teaching randomness will rise with difficulty of teaching control and evaluation increase. At present, a serious shortage of bilingual teaching in our universities and there is a big gap in teaching materials and practicality. Thus, choosing materials suitable for China situation is very important in bilingual teaching. Textbook for our bilingual education mainly divided in four types involved in imported materials, domestic publishing textbooks, own teaching materials and translated textbooks. Therefore, the evaluation of the suitability of the materials should be considered according to the type of materials and the pros and cons.

\subsection{Other teaching resources}

In addition to teachers and textbooks, other teaching resources such as syllabus, multimedia course ware is also an important indicator of the evaluation of bilingual teaching. The development of bilingual curriculum syllabus should based on the school's characteristics and professional requirements, it is necessary to take into account students 'professional training, but also focus on improving students' foreign language proficiency. To develop appropriate curriculum is to ensure the realization of the key objectives of bilingual teaching. Moreover, the multimedia course ware relying on syllabus enabling students to understand the course content, to make up the students puzzle phenomenon caused 
by student hearing or teacher pronunciation problems and follow teachers teaching schedule closely.

\section{THE TEACHING PROCESS EVALUATION}

Evaluation of classroom teaching process is an important way to test the quality of bilingual teaching. The key of implementing bilingual teaching process evaluation is to determine the scientific and feasible evaluation criteria through combine teaching content and methods or means.

\subsection{Teaching content}

Teaching content is the core of bilingual education. The mode of bilingual teaching and common teaching is different and therefore it should be arranged in accordance with the requirements of professional training objectives in teaching content design, coordinating contradictory between courses information and language. The teaching content evaluation should focus on whether the explicit purpose of teaching, teaching content is consistent therewith; proportion of foreign language teaching and fluency degree; systematic of course content and dynamically reflect the development of the subject, etc.

\subsection{Teaching methods and means}

Choice of teaching methods plays an important role in the teaching process, but also an important measure of teaching evaluation factors. Firstly, teachers should flexible use of a variety of appropriate teaching methods such as teacherstudent interaction, focusing on inspiration, individualized based on the course content and student characteristics, effectively mobilize the enthusiasm of students, promote the foreign language proficiency of students and improve learning ability. In addition, teachers should be able to properly and fully use modern educational technology to carry out multimedia course ware, network-assisted teaching and other educational means to promote teaching activities, stimulate students' interest in learning and improve teaching effectiveness. Finally, the teacher should focus on linking theory with practice in the classroom organization to guide students to extracurricular learning and train students self-learning ability.

\section{THE EVALUATION OF TEACHING EFFECTIVENESS}

Evaluation of teaching effectiveness is a necessary means for colleges and universities to strengthen the bilingual teaching quality management, as well as the important measures and methods to test teachers' professional level, teaching methods, student learning and knowledge.

\subsection{Teacher teaching effectiveness evaluation}

Evaluation of teachers teaching effectiveness mainly includes two results from the competent department in charge of teaching and student evaluation of teaching. For the evaluation of the competent department in charge of teaching, colleges and universities can monitor the entire process and the quality of teaching by setting up the supervise group and establishing teaching quality information feedback. On student evaluation of teaching, Office of Academic Affairs can organize students to do online teaching evaluation per semester and evaluate teaching attitude, content, methods and effectiveness comprehensively, and the evaluation results linked with the teacher assessment.

\subsection{The student learning effectiveness evaluation}

Evaluation of the effect on student learning is a key measure of whether the bilingual teaching mode success or not. It is not only to test the effect of bilingual learning, but also focus on training bilingual thinking in the evaluation process. The student learning effectiveness evaluation can be completed through student self-evaluation and teacher assessment. Student self-evaluation should mainly refers to the students judge the degree of satisfaction of bilingual teaching for evaluation reference from themselves bilingual learning attitude, interest, effort, training bilingual thinking and comprehensive ability improvement. Teacher assessment should evaluate the bilingual learning effectiveness of the students comprehensively and examine the integrated use capacity of learned knowledge by taking oral and written test.

\section{CONCLUSIONS}

The teaching evaluation based on CBI naturally double or even triple adapt to its objectives. That is, teachers should not only examine students 'mastery of subject content and the ability to use, but also to examine students' mastery of academic language and ability to use, also examine whether students can smoothly and correctly use second or foreign language to express academic insights, debate, discussion and academic writing. When teachers determine the curriculum goals, in fact, will determine the direction of the assessment at the same time.

Further in-depth research on bilingual teaching theory and practice, in order to deepen the theory 
discussion of bilingual curriculum and teaching; promote foreign language teaching innovative reform in non-English departments in domestic university; train all kinds of teachers "curriculum designers" awareness and ability in university nonEnglish departments to promote their professional development, so that gradually make teachers become conscious of curriculum designers and ultimately establish individualized bilingual curriculum.

\section{REFERENCES}

[1] Brinton, D, Snow, M. A, \& Wesche, M. B. Content-based Second Language Instruction. Boston: Heinle \& Heinle Publishers, 1989.2.
[2] Crandall,J \& Tucker,G.R. Content-based instruction in second and foreign languages. In A. Padilla, H. H. Fairchild \& C. Valadez (Eds.), Foreign Language Education: Issues and strategies. Newbury Park, 1990, CA: Sage. 187.

[3] Wesche, M. B. Discipline-based approaches to language study: Research issues and outcomes. In M. Krueger \& F. Ryan (Eds.) Language and Content: Discipline and Content-based Approaches to Language Study. Lexington, MA: D.C. Heath, 1993.

[4] Cummins, J. The role of primary language development in promoting educational success for language minority students. In Schooling and Language Minority Students: A Theoretical Framework. Los Angeles: California State University, Evaluation, Dissemination, and Assessment Center, 1981.

[5] Integrating Language and Content: Lessons from Immersion. ED390284, 1995-12-00, Digest. ERIC Digest: $1-6$. 